\title{
Article \\ Combustion Stability, Performance and Emission Characteristics of a CI Engine Fueled with Diesel/n-Butanol Blends
}

\author{
Arkadiusz Jamrozik*(D), Wojciech Tutak (D) and Karol Grab-Rogaliński \\ Faculty of Mechanical Engineering and Computer Science, Czestochowa University of Technology, \\ 42-201 Czestochowa, Poland; tutak@imc.pcz.pl (W.T.); grab@imc.pcz.pl (K.G.-R.) \\ * Correspondence: jamrozik@imc.pcz.pl
}

check for updates

Citation: Jamrozik, A.; Tutak, W.; Grab-Rogaliński, K. Combustion Stability, Performance and Emission Characteristics of a CI Engine Fueled with Diesel/n-Butanol Blends.

Energies 2021, 14, 2817. https:// doi.org/10.3390/en14102817

Academic Editor: Karol F. Abramek

Received: 25 April 2021

Accepted: 12 May 2021

Published: 14 May 2021

Publisher's Note: MDPI stays neutral with regard to jurisdictional claims in published maps and institutional affiliations.

Copyright: (c) 2021 by the authors. Licensee MDPI, Basel, Switzerland. This article is an open access article distributed under the terms and conditions of the Creative Commons Attribution (CC BY) license (https:// creativecommons.org/licenses/by/ $4.0 /)$.
Abstract: The development of compression ignition engines depends mainly on using alternative fuels, such as alcohols. The paper presents the results of tests of a stationary compression ignition engine fueled with mixtures of diesel oil and n-butanol with an energy share from 0 to $60 \%$. The combustion and emission results of a dual-fuel engine were compared to a conventional diesel-only engine. As part of the work, the combustion process, including changes in pressure and heat release rate, as well as exhaust emissions from the test engine, were investigated. The main operational parameters of the engine were determined, including mean indicated pressure, thermal efficiency and specific energy consumption. Moreover, the stability of the engine operation was analyzed. The research shows that the $60 \%$ addition of n-butanol to diesel fuel increases the ignition delay (by 39\%) and shortens the combustion duration (by $57 \%$ ). In addition, up to $40 \%$, it results in increased $\mathrm{p}_{\max }$ $H R R_{\max }$ and $P P R_{\max }$. The engine was characterized by the highest efficiency, equal to $41.35 \%$ when operating on DB40. In the whole range of alcohol content, the dual-fuel engine was stable. With the increase of n-butanol content to $40 \%$, the emission of $\mathrm{NO}_{\mathrm{x}}$ increased. The lowest concentration of $\mathrm{CO}$ was obtained during the combustion of DB50. After the initial increase (for DB20), the THC emission was reduced to the lowest value for DB40. Increasing the energy share of alcohol to $60 \%$ resulted in a significant, more than 43 times, reduction in soot emissions.

Keywords: co-combustion; ignition delay; combustion duration; diesel; n-butanol; emission

\section{Introduction}

The search for alternative fuels for diesel engines has been the subject of research for many years and is continuously carried out by both car concerns and research centers worldwide. Due to their high thermal efficiency, reliability, fuel economy and reliability, diesel engines are widely used in transport and various types of industrial production systems [1]. To meet future stringent emissions standards, innovative diesel engine technology, exhaust after-treatment and clean alternative fuels are required [2]. Conventional combustion of diesel fuel in a compression ignition engine is regulated by the diffusion combustion process generating high emissions of nitrogen oxides and soot, combustion products harmful to human health and the environment [3]. Ecological considerations suggest that the diesel oil used so far in diesel engines should be replaced with biofuels, i.e., renewable fuels. Alcohols are possible biofuels, including butyl alcohol, obtained from natural resources and so far used mainly in spark-ignition engines [4]. Replacing diesel fuel with alcohols applies to both traction car engines and stationary industrial engines. Stationary engines allow for a relatively simple change of the fuel system and fuel type because they are usually operated at one operating point, working with a constant, maximum load and constant control parameters [5]. Growing global energy demand and concerns about the depletion of fossil fuels are driving demand for renewable, clean energy sources. Among renewable energy sources, alcoholic fuels are often described as "green" in terms 
of their life cycle. $\mathrm{CO}_{2}$ released from alcoholic fuels used to power internal combustion engines can be offset by $\mathrm{CO}_{2}$ captured by crops used to produce these fuels. As a result, engines running on alcohol blends produce less net $\mathrm{CO}_{2}$ than conventional fossil-fuel vehicles [6].

Alcoholic fuels, such as butanol, are not ideal fuels for diesel engines because they differ from diesel fuel mainly in the higher auto-ignition temperature and the associated low cetane number $[7,8]$. These features prevent the alcohols from self-ignition in the cylinder of the $\mathrm{CI}$ engine and can only be burned with the participation of a more reactive fuel, such as diesel fuel, which initiates the ignition of the mixture. In addition, alcohols are characterized by the high latent heat of vaporization, lowering the temperature in the combustion chamber and a lower calorific value than diesel fuel. On the other hand, alcohols as oxygenated fuels can significantly increase the oxygen concentration in the combustion process, favoring the oxidation of the fuel and the burning of unoxidized exhaust components. As a result, they help improve the engine's ecological properties, reducing the emission of hydrocarbons, soot and carbon monoxide. Moreover, oxidized fuels can radically reduce the emission of soot and particulate matter [9]. Many experimental studies have shown that mixing oxidized fuel with diesel fuel can reduce smoke and improve the complex relationship between soot and $\mathrm{NO}_{\mathrm{x}}$ [10]. Among alcoholic fuels, the most commonly used are ethyl alcohol and methyl alcohol [11]. Research on ethanol co-combustion with conventional fuels in a modern combustion system for $\mathrm{CI}$ engines has been conducted for many years at the Istituto Motori, among others by Di Blasio [12-14]. They aim to find the optimal compromise between $\mathrm{NO}_{\mathrm{x}}$ and soot and to improve $\mathrm{CO}_{2}$ emissions from the diesel engine. Recently, however, it is butanol that attracts more attention than ethanol and methanol because its properties are similar to those of fossil fuels [15]. It is a fuel that can simultaneously reduce harmful engine emissions, and produced from biomass can potentially reduce the carbon footprint and improve energy security [16]. In addition, higher alcohols, such as butanol, are better suited to blending with diesel fuel than lower alcohols, such as methanol and ethanol, due to their higher energy content per unit of weight, blend stability, low corrosivity and lower miscibility with water [2].

The use of alcoholic fuels to power internal combustion engines, especially sparkignition engines, has been used repeatedly $[17,18]$. Recently, attempts have been made to use these fuels in compression ignition engines [19]. To enable the co-combustion of alcohol with diesel fuel in a CI engine, the fuel mixture should be first prepared [2]. Preparation of the mixture can take place outside the cylinder or inside the engine cylinder. In the first case, both fuels are mixed in appropriate proportions, and the mixture is injected with the existing injection system $[20,21]$. Thanks to this solution, the compression ignition engine performs automatic ignition of the premixed charge (partially premixed compression ignition (PPCI)) [1,22,23]. In the case of the method of preparing a combustible mixture inside the cylinder, an additional power supply system is used, thanks to which the so-called alcohol fumigation (fuel with low reactivity), carried out by its injection into the intake manifold (it enters the cylinder during the intake stroke) or by direct injection into the cylinder. Diesel oil (fuel with high reactivity) is injected with a standard directinjection system [24]. This ignition and combustion mode is called reactivity controlled compression ignition (RCCI [25-27]. PPCI and RCCI are combustion modes having the characteristics of both conventional diesel combustion and a compression ignition system and the homogeneous charge compression ignition (HCCI). Both PPCI and RCCI allow for the control of ignition initiation and implementing low-temperature combustion (LTC), enabling the potential simultaneous reduction of $\mathrm{NO}_{\mathrm{x}}$ and soot emissions and improvement of the thermal efficiency of the engine [28]. Blending and fumigation techniques are the most preferred methods of ignition and combustion of alcoholic fuels in diesel engines [9]. Pan et al. [29], using the mixing technique, investigated the effect of n-butanol on combustion and emissions of a common rail diesel engine with a mixture of $50 \%$ alcohol. Compared to diesel fuel, the results showed that cylinder pressure and heat release rate increased during combustion of the butanol/diesel fuel mixture. The thermal efficiency in- 
creased by $3 \%$ over diesel fuel. Butanol helped to effectively reduce soot emissions but also resulted in higher $\mathrm{NO}_{x}$ and $\mathrm{CO}$ emissions. Experimental research on the co-combustion of n-butanol with a mixture of used tire pyrolysis oil and diesel fuel (TDF) was carried out by Karagöz [30]. Experiments have shown that using high doses of TDF in a fuel mixture causes a significant increase in $\mathrm{NOx}, \mathrm{CO}$, and $\mathrm{HC}$ emissions. However, by adding n-butanol (up to 15\%), the emission of these components can be reduced. For mixtures of TDF with alcohol, a reduction in the specific fuel consumption (BSFC) was achieved. Due to the high proportion of n-butanol in the mixture with TDF, the engine's thermal efficiency (BTE) has improved. It was found that a mixture of n-butanol, diesel fuel and tire pyrolysis oil can be used in a compression-ignition engine without the need to modify it, improving its performance and emissions. Xiao et al. [31] researched combustion and emissions of a four-cylinder direct-injection diesel engine powered by a mixture of diesel fuel with 10\%, $20 \%$ and $30 \%$ n-butanol. Cylinder pressure, heat release rate, ignition delay and emissions were measured. With the increase in the proportion of n-butanol, the ignition delay period was extended, and the burning time was shortened. After the addition of n-butanol, the emission of $\mathrm{HC}, \mathrm{NO}_{\mathrm{x}}$ increased, while the emission of $\mathrm{CO}$ decreased. The increased share of n-butanol also contributed to reducing soot emissions. Altun et al. [32] achieved significant soot reduction by combusting $n$-butanol blends with diesel fuel and biodiesel for three engine loads. Cheng et al. [1] investigated, inter alia, the impact of injection advance on the emission of an engine powered by mixtures of diesel fuel and n-butanol. The results showed that both early and late injection have significant ignition retardation, resulting in a long premixed duration, allowing for a more homogeneous mixture in the engine cylinder and significantly reducing soot emissions. The purpose of the work [15] was to investigate the emission characteristics of a single-cylinder compression-ignition engine powered by a mixture of diesel oil and hydrated n-butanol. The tested mixtures were: DB10W2 (diesel oil/10\% n-butanol/2\% water) and DB10W5 (diesel oil/10\% n-butanol/5\% water). It was found that the combustion of the mixtures was accompanied by increased THC and $\mathrm{CO}$ emissions and a decrease in $\mathrm{NO}_{x}$ and PM emissions compared to diesel fuel. Sahin et al. [9] investigated a CI car engine's performance and exhaust emissions with turbocharging for two n-butanol co-combustion systems with diesel fuel. In the first, a mixing technique was used, and a mixture of n-butanol and diesel fuel was supplied to the engine. In the second case, n-butanol was delivered via a carburetor system to the intake manifold (n-butanol fumigation technique), and diesel fuel was injected into the engine cylinder. Experiments were carried out for $2 \%, 4 \%$ and $6 \% \mathrm{n}$-butanol shares. The test results showed that exhaust smoke was significantly reduced when both methods were used. However, the smoke reduction factors for the fumigation technique were higher than for the mixed technique. The experiments conducted by Kattela et al. [33] on a CI engine powered by mixtures of diesel oil and n-butanol with a volume fraction of $10 \%, 20 \%$ and $30 \%$ showed that with increased butanol content, the emission of $\mathrm{CO}, \mathrm{NO}_{\mathrm{x}}$ and smoke decreases, while the emission of unburned hydrocarbons (UBHC) increases.

As can be seen from the literature review, the results of studies on the combustion of mixtures of diesel fuel with n-butanol focus primarily on engine exhaust emissions and are often ambiguous. Therefore, they require further detailed research. Moreover, in most cases, they concern car engines for which engine stability, including the repeatability of its successive cycles, has not been analyzed. The results included in the literature review do not directly relate to assessing the impact of the fuel type on the stability of the combustion process. The repetitive combustion process in the subsequent cycles of the engine's operation translates into stable operation of the engine and the device driven by the engine. Changing the engine fuel, and each fuel mixture is a different fuel, significantly affects the combustion stability. This article presents the results of tests of a stationary compression ignition engine powered by mixtures of diesel oil and n-butanol, for which the energy share was $10 \%, 20 \%, 30 \%, 40 \%, 50 \%$ and $60 \%$. The research included not only the analysis of the mixture combustion process and emissions but also evaluating the stability of the dual-fuel engine operation. The issue of stability is particularly important 
for industrial stationary engines used as a drive for generating sets. In this type of engine, the high uniqueness of successive cycles of operation adversely affects the fluctuation of the rotational speed of the crankshaft and is one of the main reasons for the variability of the parameters of the generated electric current [34]. In the study, the indicators of the stable operation of the test engine were the coefficient of the uniqueness of the mean indicated pressure $\left(\mathrm{COV}_{\mathrm{IMEP}}\right)$ and the probability density of the occurrence of the mean indicated pressure $\left(\Phi_{\mathrm{IMEP}}\right)$.

\section{Experimental Setup and Procedure}

The tests were carried out on a stand where the main element was a stationary compression ignition engine equipped with an installation enabling the supply of both diesel oil and mixtures of diesel fuel with n-butanol.

\subsection{Research Engine and Apparatus}

The research engine is an air-cooled, single-cylinder, four-stroke Andoria 1CA90 engine. The basic technical data of the engine is shown in Table 1 . The engine is a naturally aspirated unit with a displacement volume of $573 \mathrm{cc}$ and working with a constant fuel injection angle of $20^{\circ}$ before the top dead center (bTDC ). The engine carries out direct fuel injection into the combustion chamber through a mechanical injector and a single-section injection pump. The engine, at its purpose, was used to drive various types of industrial machinery and equipment, including agricultural machinery. The engine is operated at a constant maximum load and a constant speed of $1500 \mathrm{rpm}$.

Table 1. Engine main specifications.

\begin{tabular}{cc}
\hline Item & \\
\hline Type of engine & Single-cylinder, 4-stroke, CI diesel engine, \\
naturally aspirated
\end{tabular}

The test stand was equipped with a data recording and acquisition system to measure combustion pressure in the engine cylinder. The system consists of a pressure sensor located inside the cylinder, an encoder for crank angle (CA) marker, a charge amplifier, a data acquisition card with an A/D converter and a PC. On the stand, it was possible to measure engine exhaust emissions thanks to using a five-gas exhaust gas analyzer and a smokemeter. The equipment used made it possible to measure both the fuel consumption and the air supplied to the engine. The diagram of the experimental stand is shown in Figure 1, and details of the apparatus used are in Table 2. 


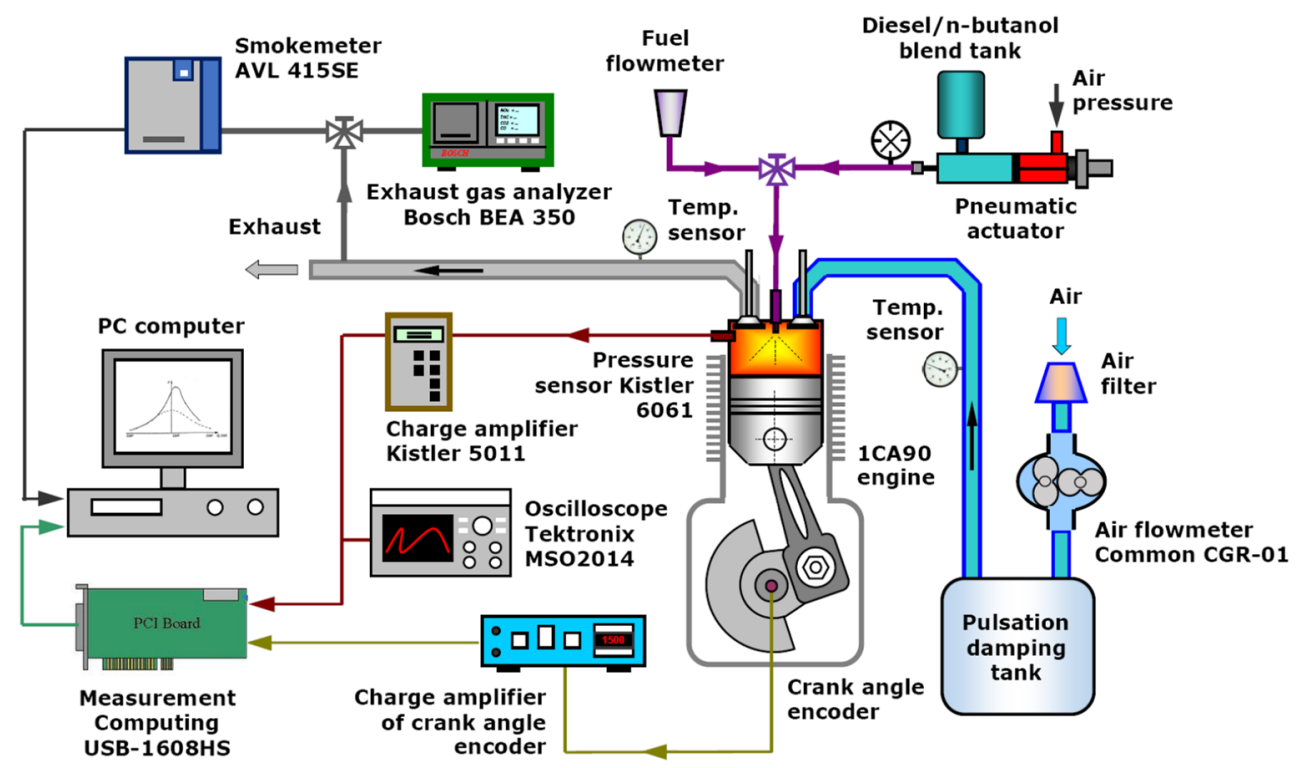

Figure 1. Test stand.

Table 2. The main instruments and equipment of the test.

\begin{tabular}{|c|c|c|}
\hline Equipment Name & Type & Precision \\
\hline In-cylinder pressure sensor & Kistler 6061 SN 298131 & $\leq \pm 0.5 \%$ FS, range: $0-25 \mathrm{MPa}$ \\
\hline Charge amplifier & Kistler 5011 & $< \pm 3 \%$ FS, range for $10 \mathrm{~V} \mathrm{FS:} \pm 10 \ldots \pm 999,000 \mathrm{pC}$ \\
\hline Data acquisition module & Measurement Computing USB-1608HS & 16 bits resolution, sampling frequency $20 \mathrm{kHz}$ \\
\hline \multirow[t]{2}{*}{ Emission equipment } & Bosch BEA 350 & $\begin{array}{l}\mathrm{CO}: \pm 0.06 \% \text { vol., } \mathrm{HC}: \pm 12 \text { ppm vol., } \\
\mathrm{CO}_{2}: \pm 0.5 \% \text { vol., } \mathrm{NO}: \pm 25 \text { ppm vol. }\end{array}$ \\
\hline & AVL Smokemeter 415SE & Soot: $\sigma \leq \pm 0.005 \mathrm{FSN}+3 \%$, range $0-10 \mathrm{FSN}$ \\
\hline
\end{tabular}

\subsection{Experimental Conditions}

In this study of the co-combustion of diesel fuel with alcohol fuel (n-butanol), a fuel mixing technique was used that does not require an additional supply system and consists of prior preparation of appropriate mixtures. In this method, a mixture of diesel fuel and $\mathrm{n}$-butanol was injected into the engine cylinder with a standard injection system. The tests were carried out at the maximum load of the engine, working at a constant rotational speed of $1500 \mathrm{rpm}$ and a constant injection timing of $20^{\circ} \mathrm{bTDC}$. They concerned a stationary engine operated in a single operating point with unchanging control parameters. The tests were carried out at a constant maximum load of the engine operating at a constant rotational speed of $1500 \mathrm{rpm}$. The tests consisted of measuring and recording cylinder pressure, fuel and air consumption, as well as exhaust emissions and smoke. Each operating point included 200 consecutive cycles of engine operation. The measurements were carried out for mixtures of diesel fuel with n-butanol, for which the energy fraction of alcohol was 10\%, 20\%, 30\%, 30\%, 50\%, and 60\%, DB10, DB20, DB30, DB40, DB50 and DB60, respectively. The co-combustion tests of diesel oil/n-butanol mixtures were compared with the results of combustion of D100 diesel oil alone as the reference fuel.

\subsection{Fuels}

Diesel fuel is a type of fuel used in compression ignition engines. The composition of diesel fuel consists of hydrocarbons (naphthenic, paraffinic and aromatic). Diesel oil is produced in the distillation processes of crude oil. In this fuel, the most important parameter is the cetane number, which determines the ability of a given type of diesel fuel to spontaneous combustion. The European standards (EN 590, EN 14214) define, inter alia, the minimum cetane number of diesel fuel for sale, which is 51 . Alcohols are an important category of oxygen-containing alternative fuels that can be added to diesel fuel to improve emissions. Alcohols can be made from natural sources, such as plants. 
Since plants absorb $\mathrm{CO}_{2}$ as they grow, combusting these fuels does not lead to additional carbon dioxide emissions $\left(\mathrm{CO}_{2}\right)$, which is one of the main greenhouse gases. Moreover, alcohols are oxidized and biologically renewable fuels, which means their use as alternative fuels or fuel additives may reduce dependence on non-renewable fossil fuels, support the local agricultural industry and increase agricultural income [9]. Among alcoholic fuels, the most common are the low alcohols, such as ethanol and methanol with short carbon chains. However, using these alcohols is associated with many problems. First of all, they are characterized by a very low cetane number, high self-ignition temperature and low calorific value. Moreover, some of them, e.g., methanol, are toxic and poisonous to humans. Low alcohols are difficult to mix with diesel fuel, making it difficult to create a uniform, durable fuel mixture. In the present research, butanol was used. It is an alcohol with a longer carbon chain because it has a much higher cetane number, a higher flame speed and calorific value than ethanol or methanol, and is also an ecological fuel that can be obtained from natural sources [6,35]. Butanol, compared to ethanol, shows better fuel properties in terms of energy content, lubricity and corrosivity of metal construction materials (tank, cylinder wall) [6]. Moreover, butanol forms a phase-stable mixture with diesel fuel that does not require additional equipment and homogenizing agents. It has lower corrosivity and lower water absorption (hydrophobicity), which can help reduce corrosion problems in fuel delivery and injection systems [1,35]. Butanol can be produced using different technologies and from many different sources (e.g., fossil fuels). Currently, natural sources are increasingly used as the raw material for the production of butanol. Biofuels, such as ethanol or butanol, can, for example, be produced by plant fermentation from lignocellulosic biomass and wood material. Recently, microalgae and microorganisms have also been perceived as good raw materials for ethanol and butanol production [6]. Table 3 shows the basic properties of diesel fuel and n-butanol.

Table 3. Fuel specifications $[9,17]$.

\begin{tabular}{cccc}
\hline Equipment Name & Unit & Diesel & n-butanol \\
\hline Molecular formula & & $\mathrm{C}_{14} \mathrm{H}_{30}$ & $\mathrm{C}_{4} \mathrm{H}_{9} \mathrm{OH}$ \\
Molecular weight & $\mathrm{g}$ & 198.4 & 74.12 \\
Cetane number & - & 51 & 25 \\
Octane number $(\mathrm{R}+\mathrm{M}) / 2$ & - & $15-25$ & 87 \\
Boiling point & $\mathrm{K}$ & $453-643$ & 390 \\
Liquid density & $\mathrm{kg} / \mathrm{m}^{3}$ & 840 & 810 \\
Lower heating value $(\mathrm{LHV})$ & $\mathrm{MJ} / \mathrm{kg}$ & 42.5 & 33.1 \\
Latent heat of evaporation $(\mathrm{LHE})$ & $\mathrm{kJ} / \mathrm{kg}$ & 243 & 581.4 \\
Autoignition temperature & ${ }^{\circ} \mathrm{C}$ & 230 & 343 \\
Stoichiometric air-fuel ratio & - & 14.6 & 11.2 \\
Viscosity (at $\left.25^{\circ} \mathrm{C}\right)$ & $\mathrm{mPa} \cdot \mathrm{s}$ & 2.419 & 2.593 \\
Carbon $(\mathrm{C})$ mass fraction & $\%$ & 85 & 64.8 \\
Hydrogen $\left(\mathrm{H}_{2}\right)$ mass fraction & $\%$ & 15 & 13.6 \\
Oxygen $\left(\mathrm{O}_{2}\right)$ mass fraction & $\%$ & 0 & 21.6 \\
\hline
\end{tabular}

The energy content of n-butanol in mixtures with diesel fuel changed from 0 to $60 \%$. Figure 2 shows the energy and mass of the fuel dose supplied to the engine for each cycle of its operation for each n-butanol fraction. It can be seen that maintaining a constant load did not guarantee a constant dose of energy and a constant mass of the mixture of both fuels. The highest dose of energy, equal to $1006 \mathrm{~J} / \mathrm{cycle}$, was characteristic for the combustion of diesel oil and the lowest for the co-combustion of diesel fuel with a $40 \%$ share of n-butanol (907 J/cycle). The reason for this was the higher thermal efficiency obtained for the DB40. Due to the differences in the density of diesel fuel and n-butanol, the mass of the mixture also changed. The largest mass was delivered during the co-combustion of diesel fuel with the highest share of n-butanol-DB60. It was $27 \mathrm{mg} /$ cycle. 


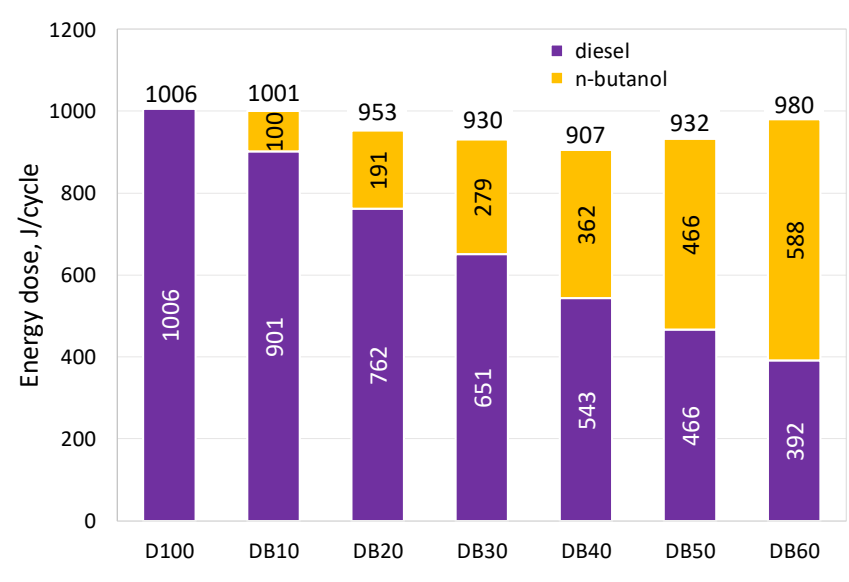

(a)

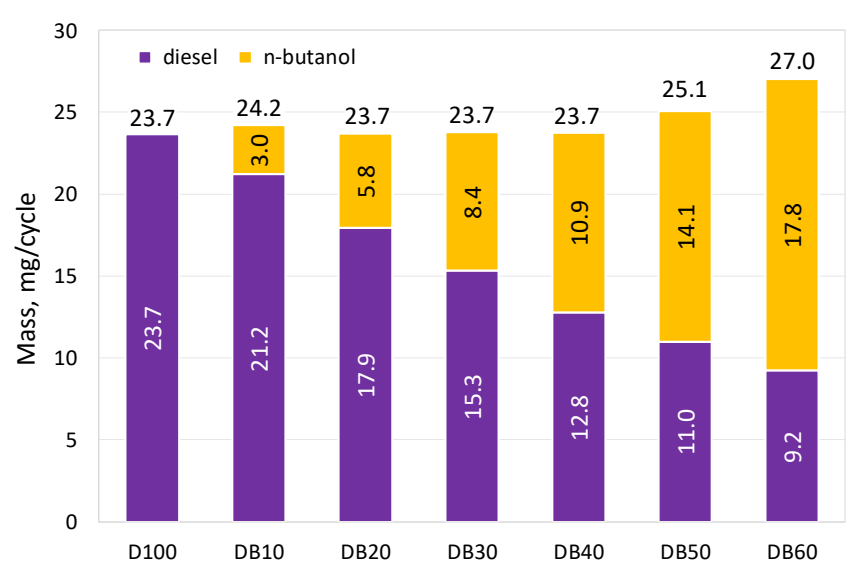

(b)

Figure 2. Effect of adding n-butanol to diesel on the energy dose (a) and the mass (b) of fuel delivered in each engine cycle.

Butyl alcohol is an example of an oxygenated fuel in which $21.6 \%$ by weight is oxygen. $64.8 \%$ by weight is carbon, and the rest, $13.6 \%$, is hydrogen. Figure 3 shows the changes in the percentages of these three elements in diesel fuel mixtures with n-butanol. It can be seen that with the increase in the percentage of n-butanol in the mixture, the oxygen content increases, reaching the highest value of $14.2 \%$ for DB60. For this mixture, the mass fraction of carbon was $71.1 \%$. The increase in the proportion of oxygen and the decrease in the proportion of carbon in the mixture affect combustion and engine exhaust emissions.

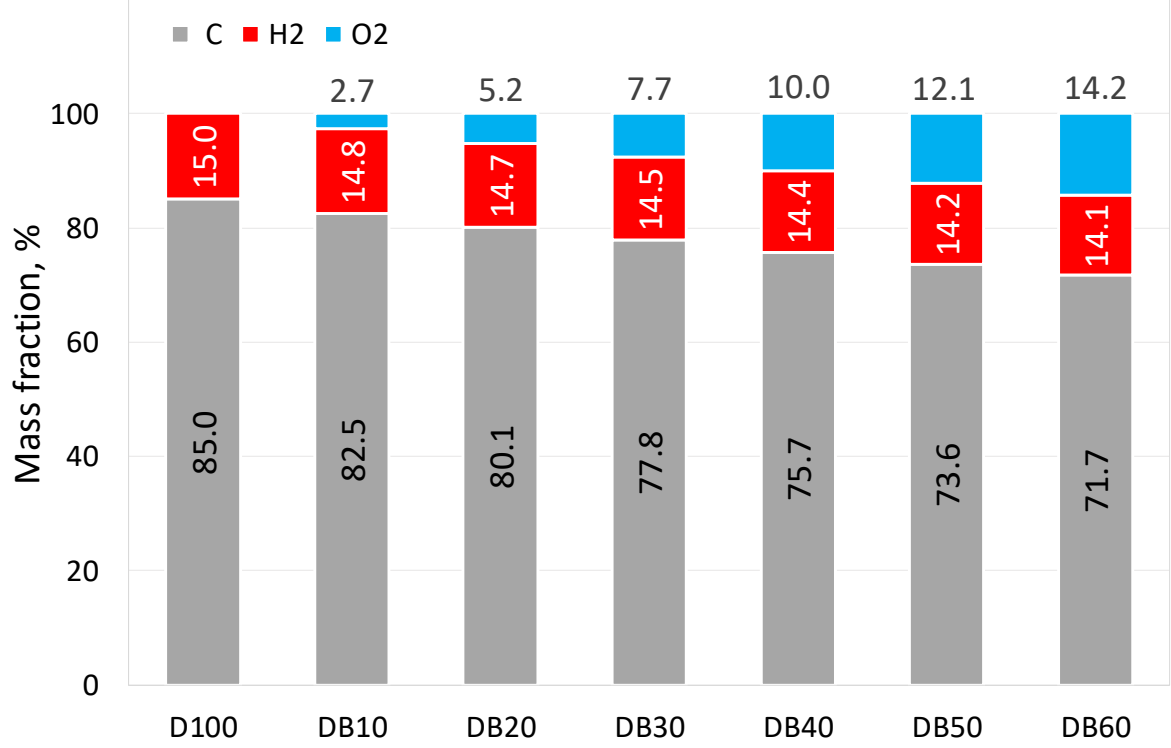

Figure 3. Mass of carbon, hydrogen and oxygen in a dose of fuel supplied for one cycle of the engine.

Changes in the percentage of n-butanol in the mixture with diesel fuel change the physicochemical properties of the charge delivered to the engine. Table 4 presents the basic properties of diesel fuel mixtures with n-butanol, which have a significant impact on the course of the combustion process and engine emission. The increase in the percentage of $\mathrm{n}$-butanol causes, inter alia, a decrease in the calorific value and increased the latent heat of vaporization of the mixture injected into the engine cylinder. For DB60 compared with D100, there was a decrease in LHV by $14.6 \%$ from 42.5 to $36.3 \mathrm{MJ} / \mathrm{kg}$ and increased LHE by $81.4 \%$ from $260 \mathrm{~kJ} / \mathrm{kg}$ to $471.6 \mathrm{~kJ} / \mathrm{kg}$, respectively. 
Table 4. Composition of diesel-n-butanol blends.

\begin{tabular}{cccccccc}
\hline Properties & D100 & DB10 & DB20 & DB30 & DB40 & DB50 & DB60 \\
\hline Diesel energetic fraction, \% & 100 & 90 & 80 & 70 & 60 & 50 & 40 \\
n-Butanol energetic fraction, \% & 0 & 10 & 20 & 30 & 40 & 50 & 60 \\
Diesel mass fraction, \% & 100 & 88 & 76 & 65 & 54 & 44 & 34 \\
n-Butanol mass fraction, \% & 0 & 12 & 24 & 35 & 46 & 56 & 66 \\
Density, kg/m 3 & 840.0 & 836.2 & 832.7 & 829.3 & 826.2 & 823.1 & 820.2 \\
LHV, MJ/kg & 42.5 & 41.3 & 40.2 & 39.2 & 38.2 & 37.2 & 36.3 \\
LHE, kJ/kg & 260.0 & 300.1 & 338.1 & 374.1 & 408.2 & 440.7 & 471.6 \\
C mass fraction, \% & 85.0 & 82.5 & 80.1 & 77.8 & 75.7 & 73.6 & 71.7 \\
$\mathrm{H}_{2}$ mass fraction, \% & 15.0 & 14.8 & 14.7 & 14.5 & 14.3 & 14.2 & 14.1 \\
$\mathrm{O}_{2}$ mass fraction, \% & 0.0 & 2.7 & 5.2 & 7.7 & 10.0 & 12.1 & 14.2 \\
\hline
\end{tabular}

\section{Results and Discussion}

The experiments presented in this paper include:

- Experimental studies of combustion of mixtures of diesel fuel with n-butanol, focusing on the analysis of the pressure course in the engine cylinder $(\mathrm{p})$, the heat release rate (HRR) and the pressure increase rate (PPR);

- Determination of the basic parameters characterizing the operational properties of the engine, i.e., indicated mean effective pressure (IMEP), indicated thermal efficiency (ITE), specific energy consumption (SEC);

- Evaluation of the stability of the engine co-combusting diesel oil with n-butanol based on the coefficient of variation of the mean indicated effective pressure $\left(\mathrm{COV}_{\mathrm{IMEP}}\right)$ and the probability density of the occurrence of the mean indicated pressure $\left(\Phi_{\mathrm{IMEP}}\right)$;

- The analysis of the exhaust emissions of the engine fueled with diesel oil/n-butanol mixtures, including the emissions of $\mathrm{NO}_{\mathrm{x}}, \mathrm{THC}, \mathrm{CO}, \mathrm{CO}_{2}$, soot.

\subsection{Combustion and Engine Performance}

\subsubsection{Pressure and heat Release Rate}

Cylinder pressure and heat release rate (HRR) are important parameters for assessing the course and nature of the combustion process [35]. Figure 4 shows the changes in pressure and heat release rate (a), as well as the pressure increase rate (b) in the cylinder of the engine fueled with diesel oil and a mixture of diesel oil and n-butanol. The graphs correspond to the engine's operation with a constant load expressed as a constant indicated mean effective pressure value of IMEP $=0.68 \mathrm{MPa}$. The engine tests shown are based mainly on the results of the cylinder pressure measurement. The pressure measurement has an error depending on the piezoelectric pressure sensor error, the charge amplifier error and the error of the A/D card used for recording and acquisition of measurement data. A detailed procedure for determining pressure measurement errors was presented in the authors' earlier works on the research of a dual-fuel engine [1,36]. Based on [36], it was assumed that the measurement error of pressure in the engine cylinder was equal to $\delta p=3.0 \%$. Pressure changes as a function of the crank angle (CA) were used to calculate the average indicated pressure IMEP and the heat release rate HRR. 


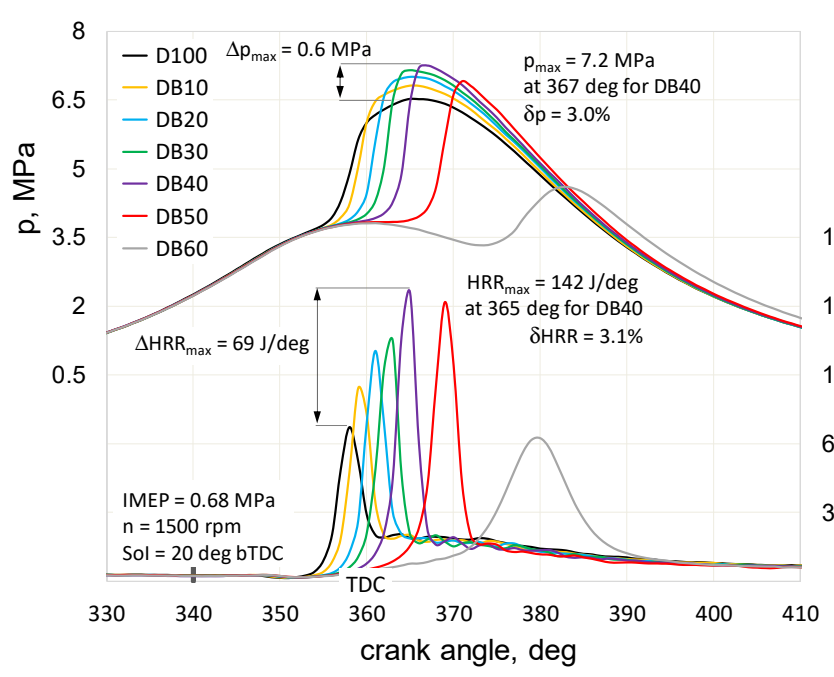

(a)

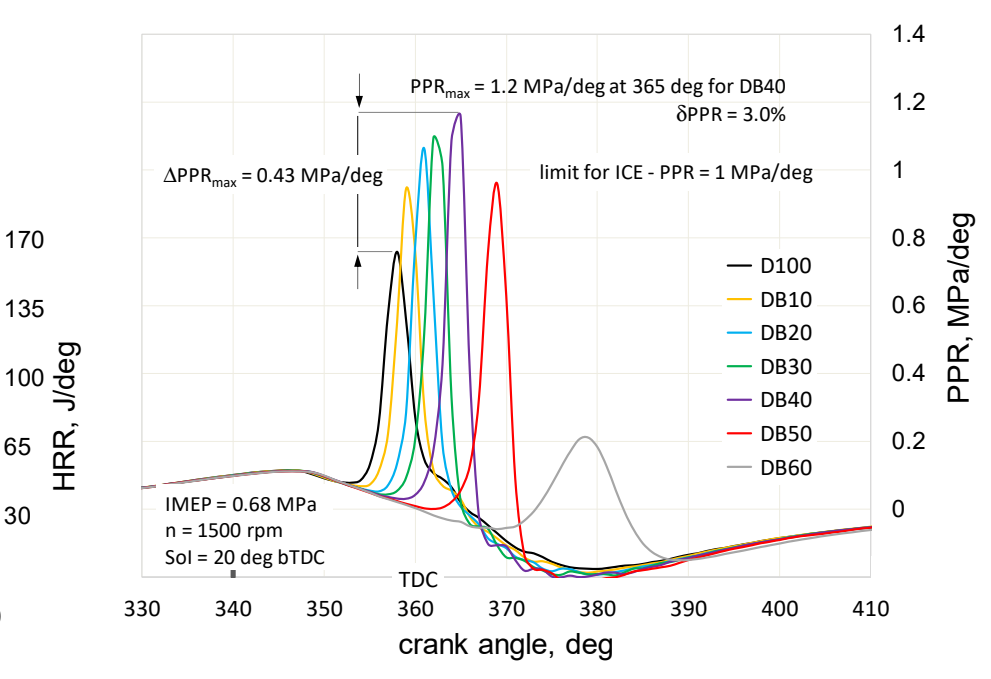

(b)

Figure 4. In-cylinder pressure and heat release rate (HRR) traces (a) and peak pressure rise (PPR) traces (b) of the engine for co-combustion of diesel fuels with n-butanol.

The indicated mean effective pressure for a single-engine cycle can be calculated from the following equation:

$$
\operatorname{IMEP}_{\mathrm{i}}=\frac{1}{\mathrm{~V}_{\mathrm{d}}} \int_{0}^{720} \mathrm{pdV},
$$

where $\mathrm{p}$ is in the cylinder pressure, $\mathrm{V}$ is cylinder volume, $\mathrm{V}_{\mathrm{d}}$ is cylinder displacement volume.

The average indicated mean effective pressure for 200 consecutive cycles is calculated based on the formula:

$$
\operatorname{IMEP}=\frac{1}{200} \sum_{\mathrm{i}=1}^{\mathrm{i}=200} \operatorname{IMEP}_{\mathrm{i}}
$$

Heat release rate calculation uses the following equation:

$$
\mathrm{HRR}=\frac{\mathrm{kp}}{\mathrm{K}-1} \frac{\mathrm{dV}}{\mathrm{d} \varphi}+\frac{\mathrm{V}}{\mathrm{K}-1} \frac{\mathrm{dp}}{\mathrm{d} \varphi}
$$

where $\mathrm{k}$ is the ratio of specific heats, $\mathrm{V}$ is cylinder volume, and $\mathrm{p}$ is the in-cylinder pressure.

As can be seen, from the above dependencies, the measurement error of IMEP and HRR is affected by the pressure measurement error and the error in determining the instantaneous changes in the cylinder volume. Detailed analysis presented in [36] allowed to estimate the values of $\delta \mathrm{IMEP}=3.1 \%$ and $\delta \mathrm{HRR}=3.1 \%$.

Changes in the energy share of butanol in the mixture with diesel oil caused changes in the combustion process, resulting in a change in engine efficiency. The indicated thermal efficiency was the indicator determining the efficiency of the test engine.

The average value of the indicated thermal efficiency of the test engine was calculated with the following formula:

$$
\mathrm{ITE}=\frac{\mathrm{IMEP} \cdot \mathrm{V}_{\mathrm{d}}}{\mathrm{Q}_{\mathrm{e}}} 100 \%,
$$

where IMEP is the indicated mean effective pressure, $V_{d}$ is the cylinder displacement volume, and $Q_{\mathrm{e}}$ is the total heat in the fuel supplied to the engine.

The presented dependence shows that the error in determining the efficiency is related to the error in determining the average indicated pressure and the measurement error of the total heat supplied to the engine. The ITE error determined according to [1] is $3.2 \%$.

In the proposed system of diesel oil and butanol co-combustion, a ready-made fuel mixture is supplied to the cylinder. The addition of alcohol increased the ignition delay 
and improved the mixing of fuel and air before combustion starts. Increasing the premixed duration is thermodynamically advantageous since all combustion is close to a constant volume process close to the ideal Otto cycle. In such a process, all heat release occurs quickly and is essentially regarded as a constant volume heat release, which helps reduce heat exchange losses and improve thermal efficiency [3]. The premixed combustion phase of alcohol/diesel blends is larger than that of diesel [37]. The ignition delay was accompanied by a pressure increase and a heat release rate (HRR) (Figure 4a). As found by Xiao et al. [31], increasing the percentage of $n$-butanol in the mixture with diesel oil increased the maximum pressure in the engine cylinder $\left(p_{\max }\right)$ and $H R R_{\max }$ obtained. These parameters first increased and then decreased along with the increase in the percentage of n-butanol. Figure 4a shows the pressure courses in the cylinder of the engine powered by the dieseln-butanol mixture. Along with the increase in the percentage of n-butanol, up to $40 \%$ of its energy content in the combusted fuel mixture increased the maximum pressure value and the angle after TDC for which this pressure value occurred was obtained. This is mainly due to the increasing LHE value of the mixture, which deteriorates the fuel evaporation process, and the low value of the cetane number of $n$-butanol, worsening the auto-ignition properties. The highest maximum pressure and maximum HRR were obtained for DB40, and they were, respectively, 7.2 MPa and $142 \mathrm{~J} / \mathrm{deg}$. Comparing the pressure course obtained for the engine powered by D100 with those obtained for the supply with n-butanol mixtures, it was found that a higher percentage of n-butanol causes a more rapid course of pressure changes with a higher rate of pressure increase. With an increased share of n-butanol, the physical and chemical properties of the fuel mixture change. The increase in ignition delay causes more fuel to combust in the kinetic combustion phase, which leads to greater pressure gains in the engine cylinder. Compared to the reference fuel D100, the maximum pressure increase was 0.6 MPA for the DB40 mixture. For the BD60 mixture, the pressure curve already shows that combustion is already too late concerning TDC. Changing the injection start angle could positively affect the combustion process and pressure changes in the engine cylinder. As the research carried out by Monsalve-Serrano et al. [38] shows, the control of fuel injection in a dual-fuel engine gives great opportunities for shaping the pressure course in the engine cylinder and thus positively influencing the engine parameters. Longer ignition delay time, improving the mixing of fuel with air, resulted in forming a premixed homogeneous mixture. In this case, premixed combustion begins to play a leading role at the expense of diffusion combustion. Premixed combustion is kinetically controlled combustion, which is very fast and violent, and characterized by a short duration, resulting in higher values of $p$ and HRR [1]. For DB60, there was a sharp drop in pressure and heat release rate due to a significant delay in the ignition and shifting the entire combustion process to the expansion stroke, far behind TDC.

The heat release analysis is the basic source of information about the combustion process in a reciprocating engine. High values of the heat release rate give information about the rapid course of combustion. The integrated area under the HRR curve gives the course of heat release, making it possible to determine the characteristic stages of combustion. The obtained results show that up to $50 \%$ of n-butanol, the $\mathrm{HRR}_{\max }$ value was higher than for the engine powered by D100. For the supply with DB40 mixture, there was increased HRR by $69 \mathrm{~J} / \mathrm{deg}$, almost double the value obtained for the supply of D100. The fast course of the combustion process is, on one hand, advantageous because the heat losses to the cylinder walls are reduced, but on the other hand, it leads to high-pressure increases, unfavorable for the engine crank mechanism. A very important parameter for an internal combustion engine, and above all for a compression ignition engine, is peak pressure rise (PPR). The maximum PRR value limits the engine operating load range and the applicability of various LTC combustion concepts. This parameter directly reflects the intensity of combustion. High PRR can cause harmful consequences, such as deterioration of engine performance and high engine noise [27]. A very high rate of heat release leads to an excessively high rate of pressure increase, limiting the operating range of the engine, 
especially in the case of high loads. The combustion of fuel-alcohol mixtures may increase PRR, caused mainly by the combustion of premixed combustion [6]. According to the literature, the acceptable level of $\mathrm{PPR}_{\max }$ is $1 \mathrm{MPa} / \mathrm{deg}$ [39]. Figure $4 \mathrm{~b}$ shows the changes in the PPR as a function of the crank angle. As in pressure and HRR, PPR max also increases to DB40, reaching 1.2 MPa/deg. The acceptable $P_{P R}$ max value was exceeded for DB20, DB30 and DB40. The high PPR $_{\text {max }}$ problem can be solved using a split injection system. However, in this study, the fuel injection system did not allow for splitting the injected fuel dose.

\subsubsection{Ignition Delay and Burn Duration}

The ignition delay period includes both the physical retardation, in which the liquid fuel breaks down into small droplets, atomizes, evaporates and entrains ambient air and the chemical retardation caused by premixing and combustion reactions. Fuel-alcohol mixtures show a clearly different ignition propensity than diesel fuel, significantly contributing to the extension of the ignition delay [6]. Figure 5a shows the normalized heat released during the combustion of diesel-n-butanol mixtures. Based on $\mathrm{Q}_{\text {norm, }}$ three combustion phases, as shown in Figure 5b, were determined, such as ignition delay (ID), the angle after TDC of $50 \%$ heat release (CA50) and combustion duration (CD). Ignition delay was defined as the time (expressed in degrees of CA) from the start of fuel injection (SoI) until 10\% of heat is released. The burning time is a time interval between $10 \%$ and $90 \%$ of the heat released. The ignition delay time (ID) is mainly influenced by fuel properties such as cetane number (CN), latent heat of vaporization (LHE) and auto-ignition temperature [35]. As can be seen, the addition and increase in the proportion of $n$-butanol in the mixture with diesel fuel increased the ignition delay. For DB60 compared to D100, an increase of $39 \%$ from $18^{\circ}$ to $35^{\circ}$ was observed. On one hand, the increased molar concentration of chemically active oxygen supplied with n-butanol shortens the chemical ignition delay. It also leads to a faster evaporation rate so that the fuel and oxygen are better mixed, which also shortens the physical ignition retardation. On the other hand, n-butanol has a much higher LHE than diesel oil, and its addition lowers the temperature in the cylinder, thus extending the ignition delay [15]. Additionally, the lower CN of n-butanol reduces the propensity of the mixture to self-ignition and increases the ID [20]. The influence of temperature on the reaction rate turns out to be greater than the molar concentration of oxygen. Therefore, the temperature in the engine cylinder is a more important factor determining the ignition delay, especially in the case of low reactivity fuel such as n-butanol [6]. In a study by Xiao et al. [31] concerning the co-combustion of biodiesel with n-butanol in a compression ignition engine, it was found that the high latent heat of vaporization of n-butanol resulted in increased vaporization of the mixture in the cylinder, which absorbed more heat and lowered the temperature in the cylinder. As the temperature decreased and the combustion conditions worsened, the maximum HRR decreased, and the fuel combustion became increasing incomplete.

The CA50 combustion phase is one of the basic parameters for assessing the combustion process and heat release efficiency [19]. The lowest CA50 was obtained for DB30 and DB40. The use of n-butanol increases the oxygen concentration in the combustible mixture, which results in the improvement of combustion conditions during the diffusion combustion period. This accelerates the combustion process, leading to increased HRR and a decrease in CA50 [35]. The increase in CA50 for DB50 and DB60 is due to deterioration in combustion and decreased HRR. As the percentage of n-butanol increased, the burning time (CD) was shortened. For DB60, compared to D100, the CD was shortened by 57\% from $51^{\circ}$ to $22^{\circ}$. First, it was due to a reduction in the surface tension and viscosity of the mixture with n-butanol, which facilitated the breakdown of large fuel drops in the combustion chamber into small droplets and improved the atomization effect, accelerating mixture formation and combustion. Moreover, the volatility of n-butanol is higher than in diesel fuel; therefore, n-butanol decomposes more easily and evaporates more efficiently than diesel fuel [9]. Second, the higher oxygen concentration in n-butanol further accelerated the 
combustion in the zone with the lower excess air coefficient $(\lambda)$ in the diffusion combustion stage. According to [35], along with the increase of n-butanol, the percentage of premixed combustion increases, and the percentage of diffusion combustion decreases, which results in a reduction of the combustion time.

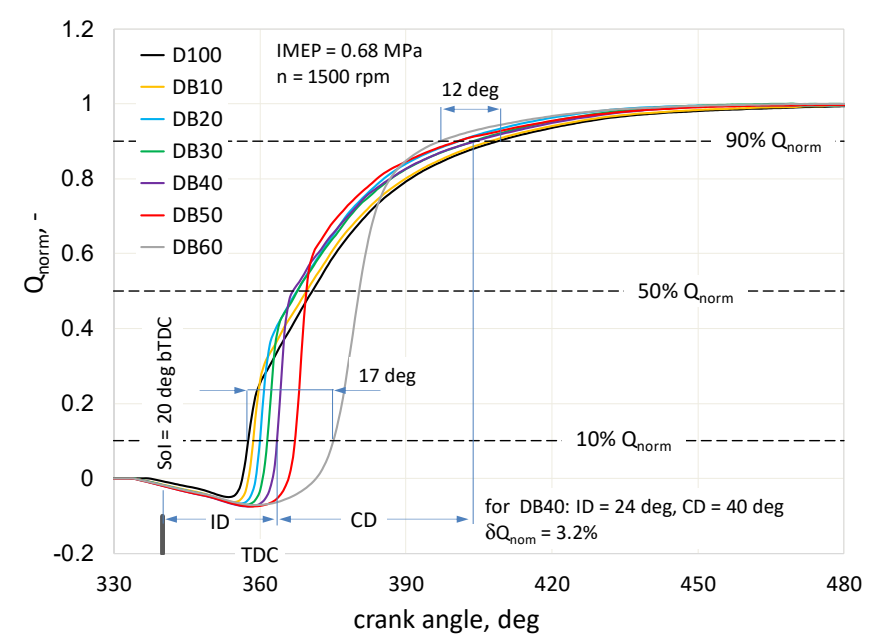

(a)

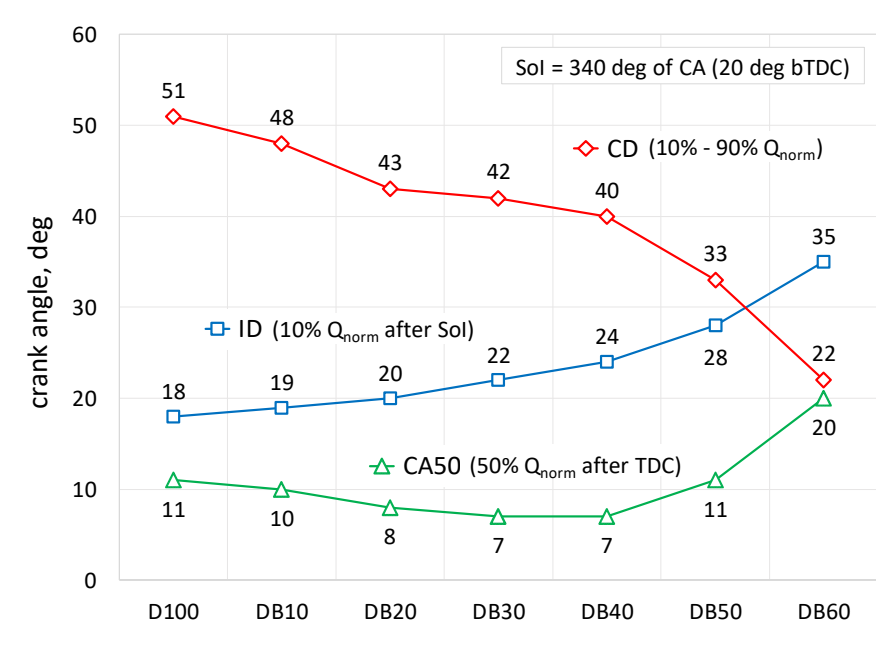

(b)

Figure 5. Normalized heat release (a) and combustion phases (b) for co-combustion of diesel with n-butanol.

\subsubsection{Indicated Thermal Efficiency and Specific Energy Consumption}

The engine's thermal efficiency is one of the main performance indicators of the internal combustion engine, characterizing its ability to convert the chemical energy of the fuel supplied to the engine into useful mechanical work [35]. Figure 6 shows the changes in indicated thermal efficiency (ITE) for an engine fueled with diesel fuel and a mixture of diesel fuel with n-butanol. The change in the ratio of n-butanol and diesel in the mixture influenced the thermal efficiency and the specific energy consumption of the test engine. Increasing the percentage of n-butanol to $40 \%$ resulted in increased ITE. The engine was characterized by the highest efficiency, equal to $41.35 \%$ when operating on a mixture with $40 \%$ alcohol content. Compared to diesel fuel, it was higher by about $11 \%$. According to [25,35], ITE increases when alcohol is added to diesel fuel. The increase in ITE was caused by the acceleration of chemical oxidation reactions and the intensification of the combustion process due to additional, active oxygen supplied to the engine cylinder along with n-butanol. The maximum HRR was achieved for the DE40. Moreover, the increase in the oxygen concentration with the increase in the percentage of n-butanol limited forming fuel-rich zones in the cylinder, leading to reducing incomplete combustion losses [35]. One of the parameters having a significant impact on the ITE value is the boiling point of both fuels [35]. The boiling point of diesel fuel is much higher than that of n-butanol. This means that the increase in the proportion of n-butanol in the mixture with diesel fuel causes a decrease in the boiling point, which leads to faster evaporation of the charge and causes micro-explosions that favor combustion. Moreover, the lower viscosity of n-butanol improves the spraying efficiency of the fuel stream [35]. Lower viscosity and density of blends lead to better fuel vaporization and help for better utilization of heating energy [40]. For DB50 and DB60, there was a decrease in ITE due to a slower combustion process and shifting its main part per expansion stroke, as shown in the HRR curves. For DB50 and DB60, there was a decrease in ITE due to slower combustion and a shift in HRR per expansion stroke. 


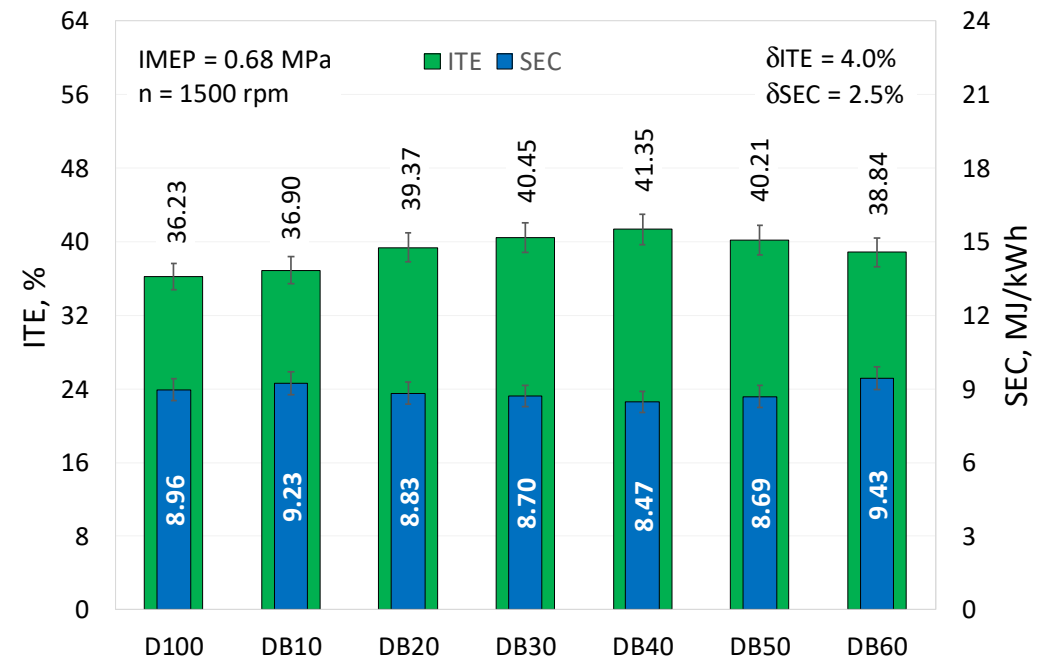

Figure 6. Indicated thermal efficiency (ITE) and specific energy consumption (SEC) in the test engine powered by diesel-n-butanol blends.

Figure 6 also shows the changes in the specific energy consumption (SEC) of an engine powered by diesel-n-butanol mixtures. SEC is expressed in MJ $/ \mathrm{kWh}$. The engine had the lowest SEC (8.47 MJ/kWh) for the DB40. As expected, the lowest SEC was obtained for the mixture with the highest thermal efficiency.

\subsection{Engine Stability}

\subsubsection{Coefficient of Variation of Indicated Mean Effective Pressure}

In an internal combustion engine, the chemical energy of the fuel is released in the combustion process and converted into mechanical work. Thanks to the crank mechanism, this energy is transferred to the outside and can drive various types of machines and devices. The combustion process in the engine cylinder is cyclical, related to the four-stroke mode and the rotational speed of the crankshaft. Due to wave phenomena in the intake system, temporary changes in the composition of the combustible mixture, the uniqueness of successive fuel injections, and random phenomena, the subsequent cycles of the engine differ and contribute to unstable engine operation. The indicator enabling assessing the stability of the internal combustion engine may be the coefficient of variation of the mean indicated effective pressure, which is defined as the ratio of the standard deviation of IMEP to the average value for the adopted set of successive cycles of operation under the conditions of the steady-state of the engine operation. The coefficient of variation of the indicated mean effective pressure was determined by the following equation:

$$
\mathrm{COV}_{\text {IMEP }}=\frac{\text { STD }_{\text {IMEP }}}{\operatorname{IMEP}} 100 \%,
$$

where $S T D_{\text {IMEP }}$ is the standard deviation in indicated mean effective pressure.

Based on the available literature, the maximum acceptable value of the coefficient of variation is determined. It is assumed that the internal combustion engine works stably when the $C O V_{\text {IMEP }}$ value does not exceed 5\% [39]. Figure 7 shows the $C_{\text {IMEP }}$ changes for the engine powered by mixtures of diesel fuel with n-butanol, determined for 200 consecutive cycles of the engine operation. It can be seen that in the whole range of alcohol content, the dual-fuel engine worked stably, and $\mathrm{COV}_{\text {IMEP }}$ both for diesel oil and mixtures of diesel fuel with n-butanol did not exceed the permissible value of $5 \%$. Up to $40 \%$ share of n-butanol in the fuel mixture, no significant influence on the combustion stability was noted $\left(\mathrm{COV}_{\text {IMEP }} \cong 2 \%\right)$. Exceeding the $40 \%$ share of n-butanol in the mixture resulted in increased uniqueness of IMEP related, inter alia, with a significant delay in combustion in relation to TDC. The operation of the DB40 powered engine was the least unique, and 
it was similar to the uniqueness of the D100. The most stable engine operation for DM40 resulted in maximum thermal efficiency (Figure 6).

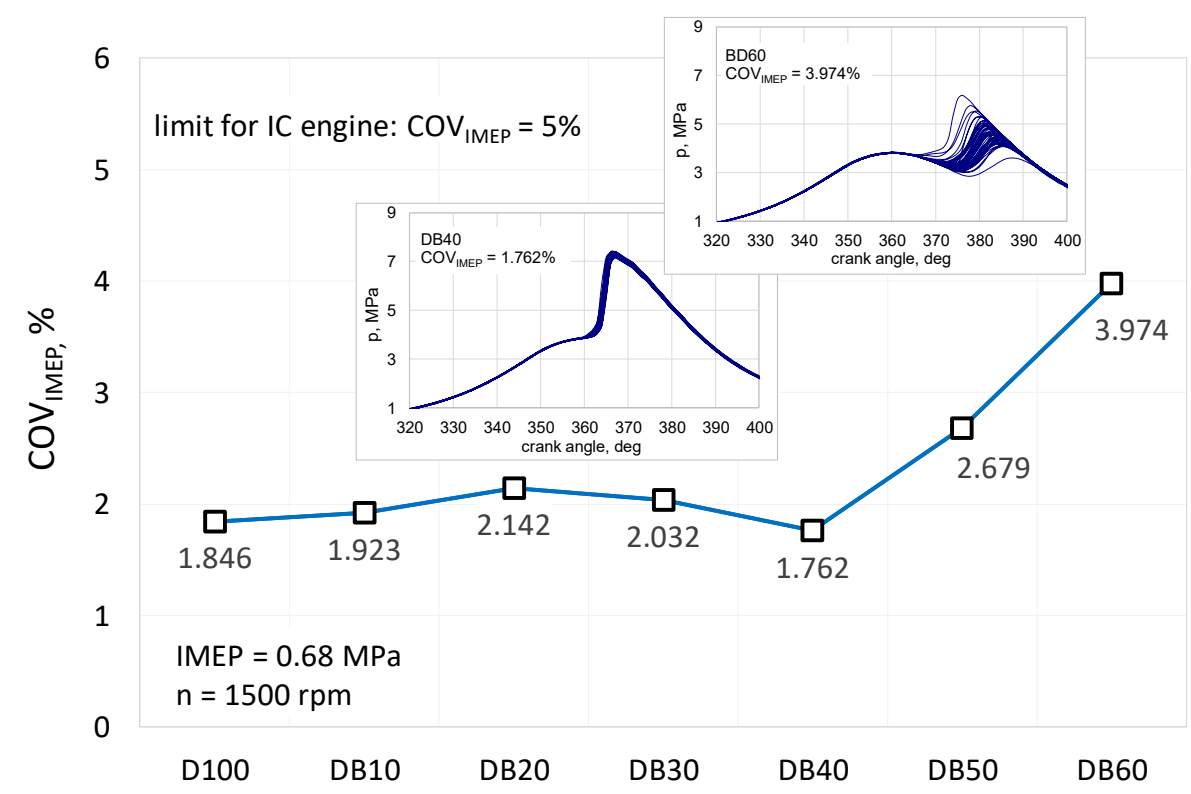

Figure 7. Coefficient of variation indicated mean effective pressure $\left(\mathrm{COV}_{\mathrm{IMEP}}\right)$ for a test engine powered by diesel-n-butanol blends.

\subsubsection{Probability Density of Indicated Mean Effective Pressure}

The probability density of the mean indicated pressure ( $\left.\Phi_{\text {IMEP }}\right)$ could be an indicator used to assess the stability and uniformity of the internal combustion engine operation [41]. It indicates the probability of an average IMEP occurring in a result set of 200 consecutive engine cycles. The probability density of mean indicated pressure:

$$
\Phi_{\mathrm{IMEP}}=\frac{1}{\operatorname{STD}_{\mathrm{IMEP}} \sqrt{2 \pi}} \exp \left(\frac{-\left(\mathrm{IMEP}_{\mathrm{i}}-\mathrm{IMEP}^{2}\right.}{2 \mathrm{STD}_{\mathrm{IMEP}}^{2}}\right),
$$

Figure 8a shows the changes of $\Phi_{\text {IMEP }}$ determined for the engine powered by a mixture of diesel fuel with n-butanol. It can be seen that the highest probability of obtaining the average value of IMEP $\approx 0.68 \mathrm{MPa}$ was associated with the combustion of diesel fuel with a $40 \%$ share of n-butanol (DB40). In this case, the maximum value of $\Phi_{\text {IMEP }}$ was 33.3 and was close to the value obtained for D100. The lowest value of $\Phi_{\text {IMEP }}$ was obtained for DB60. Based on this, it can be concluded that the engine for the DB40 was the most stable, and for the DB60, the least stable. Obtaining the best results for DB40 was related to the dynamic combustion process (max HRR) and the highest thermal efficiency of the engine. The worst results for the DB60 resulted from the deterioration of combustion due to a significant ignition delay. The analysis of the engine stability based on the IMEP probability density value confirmed the conclusions drawn based on $C O V_{\text {IMEP }}$ and showed that $\Phi_{\text {IMEP }}$ is a reliable indicator that can be used to assess the uniformity of the dual-fuel engine operation. The deterioration of the operation stability of a dual-fuel engine powered by the DB60 mixture can also be seen in the diagram showing the relationship between the maximum pressure and IMEP for 200 consecutive cycles of engine operation (Figure 8b). Compared to DB40, obtaining similar IMEP values was associated with a significant dispersion of $\mathrm{p}_{\max }$. For the DB60, it was $2.7 \mathrm{MPa}$, while for the DB 40, it was only $0.4 \mathrm{MPa}$. 


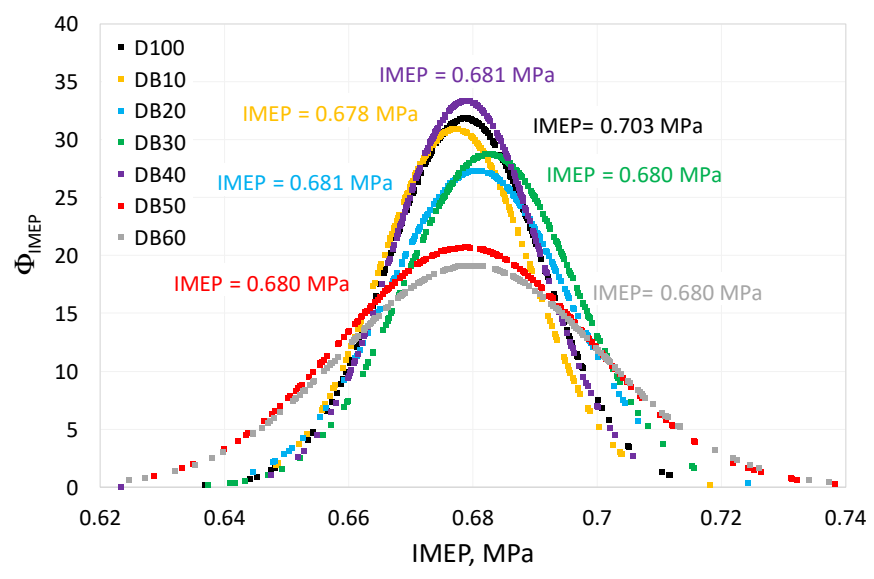

(a)

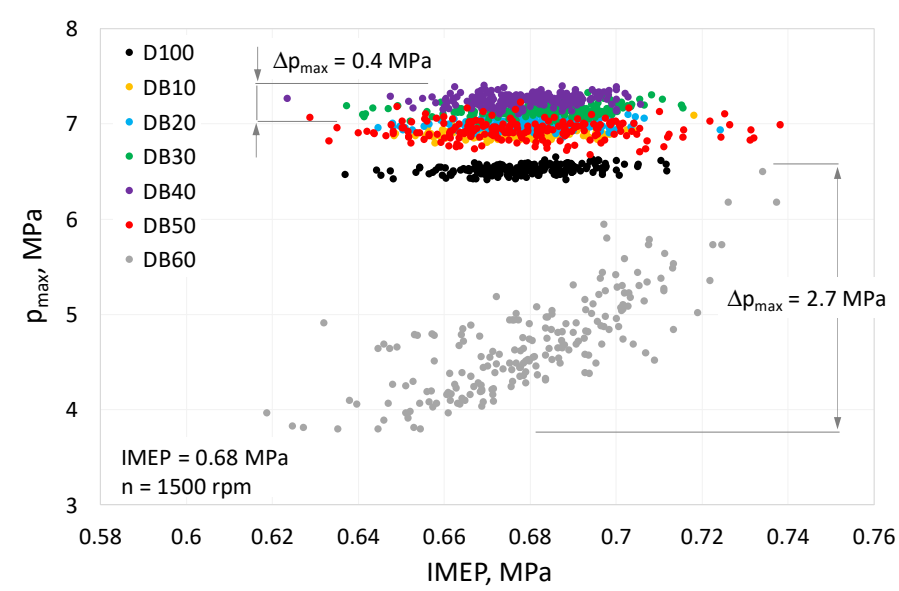

(b)

Figure 8. Probability density of indicated mean effective pressure (a) and $\mathrm{p}_{\max }$ vs. IMEP (b) for test engine powered by diesel-n-butanol blends.

\subsection{Emissions}

One of the potential benefits of using alcoholic fuels in a compression ignition engine is reducing harmful and toxic exhaust gas emissions. In compression ignition engines, due to the way the fuel is supplied to the cylinder by fuel injection, the time to prepare a premix, appropriately homogenized fuel mixture is insufficient. This leads to forming fuel-rich zones, potential sources of increased $\mathrm{HC}$ and soot emissions, and high-temperature zones, potential sources of increased $\mathrm{NO}_{\mathrm{x}}$ emissions [35]. Due to the properties of alcohol, such as high latent heat of vaporization or high self-ignition temperature, the ignition delay is increased, and the time to prepare the combustible mixture in the cylinder is increased. This leads to the improvement of the combustion process and enables reducing the concentration of harmful components in the exhaust gas. Fuel-alcohol blends show great benefits in optimizing the $\mathrm{NO}_{x} /$ soot relationship. They have $\mathrm{NO}_{x}$ emissions compared to diesel fuel but much lower soot emissions [6].

\subsection{1. $\mathrm{NO}_{\mathrm{x}}$ Emission}

As a result of fuel combustion in the cylinder of an internal combustion engine, under high-temperature and oxygen conditions, nitrogen and oxygen react to form $\mathrm{NO}$, accounting for about $90 \%$ of the $\mathrm{NO}_{x}$ released with the exhaust gas. There are two common chemical mechanisms for forming NO. The first is the thermal mechanism (Zeldovich's mechanism), and the second is the prompt mechanism (Fenimore's mechanism) [42,43]. Combustion in a diesel engine takes place with an excess air ratio above 1 and is lean combustion. Therefore, the thermal mechanism of NO formation is more important, whereby NO formation is largely influenced by the peak temperature and oxygen concentration in the engine cylinder. NO formation occurs in areas where the local temperature exceeds $1800 \mathrm{~K}$, and the rate of NO formation increases significantly with the increasing local temperature inside the cylinder [10,42]. As the n-butanol content was increased to $40 \%$, the emission of $\mathrm{NO}_{x}$ increased (Figure 9a). The emission of nitrogen oxides for DB40 compared to D100 was higher by $46 \%$. After exceeding the $40 \%$ share of n-butanol, a decrease in $\mathrm{NO}_{x}$ emissions was noted. The increase in $\mathrm{NO}_{x}$ emissions, along with the increase in the percentage of n-butanol to $40 \%$, was caused by the intensification of the combustion process (increased premixed combustion) and increased rate of heat release. In addition, the additional oxygen supplied with n-butanol first intensified combustion and increased the temperature in the engine cylinder, and second, it contributed to forming oxygen-rich zones. Xiao et al. [31] found that the increase in $\mathrm{NO}_{\mathrm{x}}$ emissions in the case of co-combustion of diesel fuel with n-butanol is mainly influenced by the extension of the ignition delay, the shortening of the combustion time and the increase of the temperature in the cylinder. After the $40 \%$ share of n-butanol was exceeded, due to the deterioration of the combustion 
process and the decrease in the heat release rate, the $\mathrm{NO}_{\mathrm{x}}$ emission decreased. Although the oxygen content in the cylinder was sufficient and promoted forming nitric oxide, due to the high proportion of alcohol and its high latent heat of vaporization, there was a temperature drop in the cylinder, which determines $\mathrm{NO}_{\mathrm{x}}$ formation.

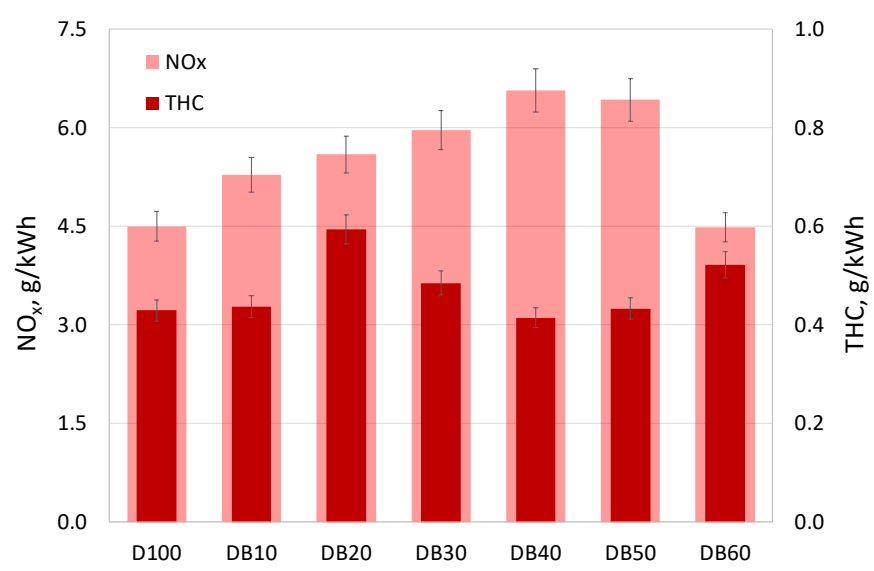

(a)

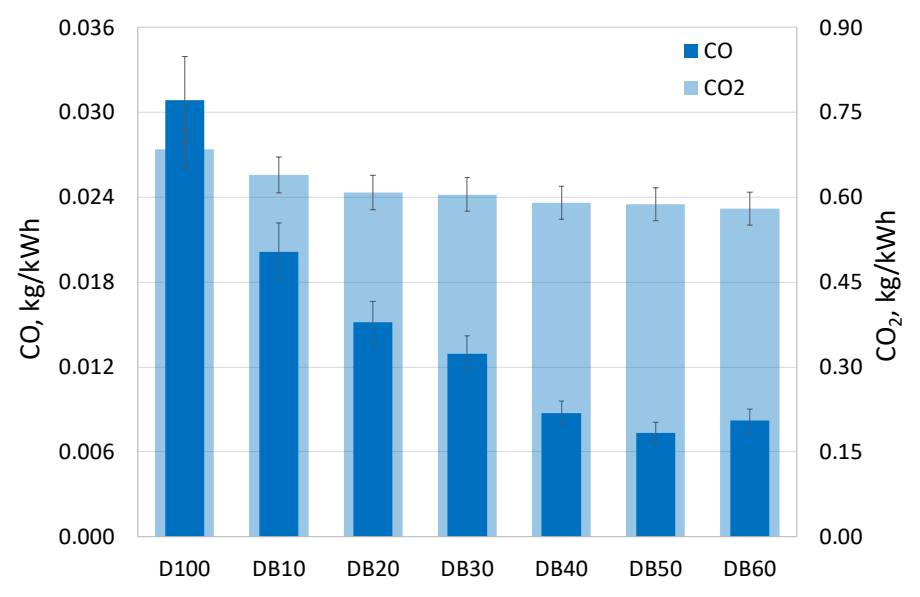

(b)

Figure 9. Specific emission of $\mathrm{NO}_{x}$ and THC (a) and $\mathrm{CO}$ and $\mathrm{CO}_{2}(\mathbf{b})$ for test engine powered by diesel-n-butanol blends.

\subsubsection{THC Emission}

THC is a product of incomplete combustion. Excessive compaction (or excessive dilution) of the mixture and low temperature increases the emission of THC [35]. Initially, the co-combustion of diesel fuel with n-butanol (up to $20 \%$ ) favored forming hydrocarbons (Figure 9a). For the DB20, compared to the D100, emissions increased by $38 \%$. Increasing the alcohol content further reduced the production of THC. The lowest concentration, comparable with D100, was obtained for DB40, and it was $0.415 \mathrm{~g} / \mathrm{kWh}$. Above $40 \%$ of n-butanol, increased THC emission was again observed, reaching the maximum value of $0.522 \mathrm{~g} / \mathrm{kWh}$ for DB60. The source of excessive THC emission is mainly unburned fuel remaining in the engine cylinder crevices, into which the flame cannot penetrate, among other things, due to the wrong direction of injection spray [39]. However, excessive depletion of the mixture caused by long ignition delay is also one of the most common sources of unburned HC emission [6]. The initial increase in THC emission was caused by the interaction of n-butanol, which because of high LHE value, extended the premixed mixture formation time and increased the probability of unburned charge deposition on the walls and inside the combustion chamber crevices [35]. The decrease in THC emissions after exceeding the $20 \%$ share of n-butanol could be caused by the presence of additional oxygen, the influence of which was greater than the influence of LHE. The additional oxygen improved combustion by diluting and leaning the mixture and eliminating fuel-rich zones in the engine cylinder. In addition, the lower viscosity of n-butanol, compared to diesel fuel, favors forming smaller fuel droplets, which improves the atomization and evaporation process and thus homogenizes the combustible mixture. Another increase in THC emissions could be caused by a significant delay in the ignition, a shift in primary combustion to the exhaust stroke and, consequently, incomplete combustion. In general, LTC concepts have a long ignition delay, which means that fuel and air are better premixed than in a conventional combustion system. Avoiding fuel-rich areas can reduce hydrocarbon emissions to some extent. However, using low reactivity fuels generally results in high $\mathrm{HC}$ emissions [6].

\subsection{3. $\mathrm{CO}$ and $\mathrm{CO}_{2}$ Emission}

The source of $\mathrm{CO}$ emissions is carbon oxidation reactions in the cylinder areas with low temperature, while $\mathrm{CO}_{2}$ is a product of complete combustion of hydrocarbon fuel under 
high-temperature conditions and oxygen availability [29]. During combustion, the carbon in the hydrocarbon fuel is oxidized to $\mathrm{CO}$, and then if the cylinder temperature is high enough and there is still enough $\mathrm{O}_{2}$ in the cylinder, $\mathrm{CO}_{2}$ is formed. Awareness of global warming and greenhouse gas (GHG) emissions raises widespread interest in reducing $\mathrm{CO}_{2}$ [6]. The amount of $\mathrm{CO}$ and $\mathrm{CO}_{2}$ emissions depend on the quality of combustion and is closely related to carbon, so it directly depends on the number of carbon atoms $(\mathrm{C})$ in the fuel. According to Han et al. [6], most of the CO generated in diffusion flame can be oxidized to $\mathrm{CO}_{2}$ during a suitably long and delayed main burning stage. Figure $9 \mathrm{~b}$ shows the $\mathrm{CO}$ and $\mathrm{CO}_{2}$ emissions for the engine running on diesel fuel with n-butanol mixtures. The addition of alcohol to diesel fuel resulted in a significant reduction of $\mathrm{CO}$ emissions and a slight decrease in $\mathrm{CO}_{2}$ emissions. The lowest concentration of carbon monoxide was obtained during the combustion of DB50, and it was $76 \%$ lower compared to D100. The reduction in CO emissions is related to additional oxygen in the cylinder, supplied with an increasing proportion of n-butanol, which caused the oxidation of $\mathrm{CO}$ to $\mathrm{CO}_{2}$. Moreover, a significant delay in ignition related to the presence of alcohol promoted forming the premixed mixture and increased the availability of free oxygen. In the case of increasing the percentage of n-butanol in the mixture with diesel fuel, not only was the amount of oxygen increased, but also the amount of carbon decreased, and consequently lower $\mathrm{CO}$ and $\mathrm{CO}_{2}$ emissions were achieved. Co-combustion of butanol with diesel fuel can increase the temperature in the late stage of the combustion process, which helps to accelerate the oxidation of $\mathrm{CO}$ to $\mathrm{CO}_{2}$. When analyzing carbon dioxide emissions, it should be remembered that n-butanol can be produced from various plant products that absorb $\mathrm{CO}_{2}$ during the growth period. Thus, the combustion of n-butanol does not lead to additional $\mathrm{CO}_{2}$ emissions [9].

\subsubsection{Soot Emission}

Soot is a major component of emitted particulate matter (PM) and is formed in the engine under high-temperature conditions and fuel-rich regions. These conditions are typical for the combustion of diesel fuel in a compression-ignition engine. Soot particles are formed very early in the process of diffusion combustion due to fuel dissociation under high-temperature conditions and a low excess air ratio $(\lambda)$. Usually, under the operating conditions of a diesel engine, most of the soot formed in the first stage of the combustion process is removed in subsequent stages of the cycle due to oxygen-rich zones [35]. The most important parameters determining the sooting process are the local air/fuel ratio (C:H and C:O ratio), temperature, pressure and time needed to oxidize the fuel. Figure 10 shows the soot emissions for an engine powered by mixtures of diesel fuel and n-butanol. It can be seen that increasing the alcohol content from 0 to $60 \%$ causes a significant reduction in soot emissions. For the DB60, compared to the D100, the emission reduction was over 43 times. In general, hydrocarbon fuels have a strong tendency to form carbonaceous particles, i.e., soot. However, alcoholic fuels, such as n-butanol, contain much less carbon, and for them, the $\mathrm{C}: \mathrm{H}$ ratio is much more favorable. This makes them not a good fuel for soot formation. Moreover, $\mathrm{n}$-butanol contains oxygen (favorable $\mathrm{C} / \mathrm{O}$ ), contributing to the oxidation of soot and reducing its emission [29]. Figure 10 shows the values of the $\mathrm{C}: \mathrm{H}$ and $\mathrm{C}: \mathrm{O}$ ratios determined for the tested diesel-n-butanol mixtures. Another reason to reduce soot emissions is the properties of n-butanol, such as high latent heat of vaporization and high temperature of self-ignition, which, by delaying the ignition, contribute to better mixing of fuel with air and creating more favorable conditions for complete combustion of the fuel in the engine cylinder [35]. It should also be noted that diesel fuel contains mainly aromatic hydrocarbons, which are perceived as having the highest soot tendency [6]. 


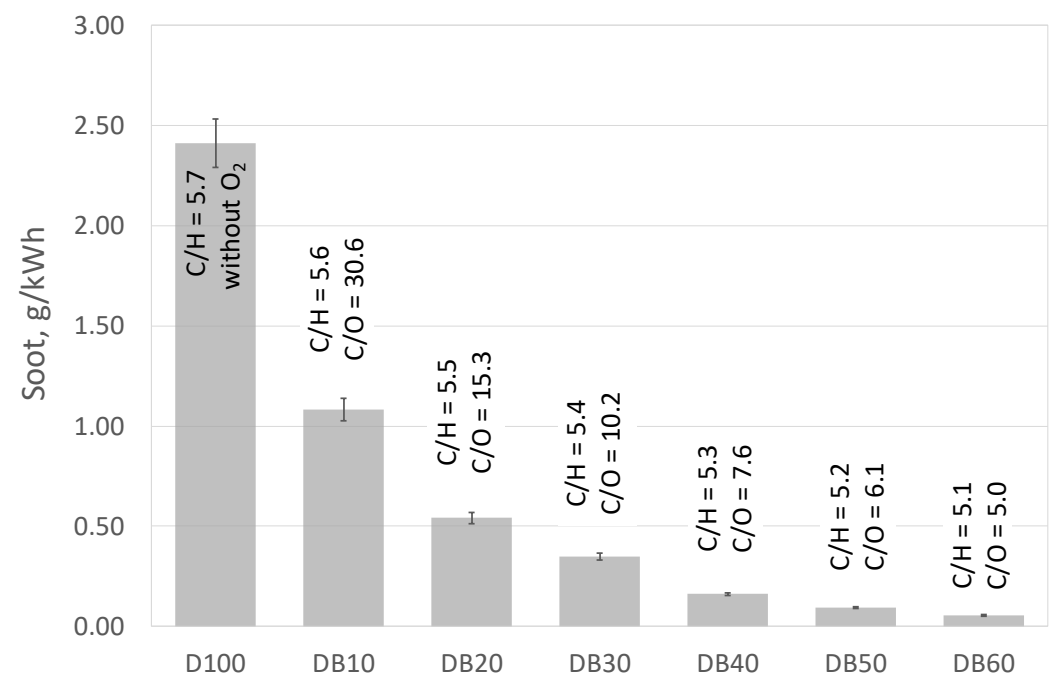

Figure 10. Specific emission of soot for test engine powered by diesel-n-butanol blends.

\section{Conclusions}

The use of alcohol as fuels for compression ignition engines can be an effective way to improve engine efficiency and find a compromise between low soot emissions and increased emissions of nitrogen oxides. The presented work shows the results of tests of a stationary compression-ignition engine, which was fed with mixtures of diesel oil and n-butanol, with an energy share from 0 to $60 \%$. Based on the research, the following conclusions can be drawn:

Assessment of the combustion process:

- The increase of the energy content of n-butanol in the mixture with diesel oil caused increased $p_{\max }, \mathrm{HRR}_{\max }$ and $\mathrm{PPR}_{\max }$. The highest values were obtained for $40 \%$ alcohol content, and they were, respectively, 7.2 MPa, 142 J/deg and 1.2 MPa/deg.

- With the increase in the percentage of n-butanol, the ignition delay (ID) was increased, but the combustion time (CD) was shortened. For DB60 compared to D100, increased ID of $39 \%$ from $18^{\circ}$ to $35^{\circ}$, the CD was shortened by $57 \%$ from $51^{\circ}$ to $22^{\circ}$.

- The share of n-butanol increased the efficiency of the engine. The highest value was obtained for DB40, which was $11 \%$ higher than in D100.

- Up to $40 \%$ of n-butanol, there was no impact on the stability of combustion (COV $\mathrm{COMEP}_{\text {IMEP }}$ $\cong 2 \%$ ), for DB40, the highest maximum value of $\Phi_{\text {IMEP }}$ was obtained, equal to 33.3.

Emissions:

- With the increase of n-butanol content to $40 \%$, the emission of $\mathrm{NO}_{\mathrm{x}}$ increased. The emission of nitrogen oxides for DB40 compared to D100 was higher by $46 \%$. After exceeding the $40 \%$ share of n-butanol, a decrease in $\mathrm{NO}_{x}$ emissions was noted.

- $\quad$ The highest THC value was obtained for DB20 and was higher than D100 by 38\%. For the remaining shares of n-butanol, there were no significant differences.

- The addition of alcohol to diesel fuel resulted in a significant reduction in CO emissions and a slight decrease in $\mathrm{CO}_{2}$ emissions. The lowest concentration of carbon monoxide was obtained during the combustion of DB50, and it was 76\% lower compared to D100.

- Increasing the energy share of n-butanol from 0 to $60 \%$ results in a significant reduction of soot emissions. For the DB60, compared to the D100, the emission reduction was over 43 times.

The use of n-butanol as an additive to diesel fuel gives benefits in the form of increased engine efficiency and a very beneficial effect on reducing soot in the engine exhaust. The presented results cover only a part of the description of the co-combustion of these fuels. The influence of n-butanol share on the stability of the combustion process was shown. The next step should be optimizing the fuel injection timing, using a modern supply 
system with the possibility of dividing the dose of the injected fuel, and using exhaust gas recirculation to reduce $\mathrm{NO}_{x}[44]$.

Author Contributions: Conceptualization, A.J., W.T. and K.G.-R.; data curation, A.J., W.T. and K.G.-R.; formal analysis, A.J.; investigation, A.J., W.T. and K.G.-R.; methodology, A.J. and W.T.; writing-original draft, A.J.; writing—review and editing, W.T. and K.G.-R. All authors have read and agreed to the published version of the manuscript.

Funding: This research was funded by the Ministry of Science and Higher Education of Poland from the funds dedicated to scientific research No. BS-PB-1-100-3011/2021/P.

Conflicts of Interest: The authors declare no conflict of interest.

\section{References}

1. Cheng, X.; Li, S.; Yang, J.; Liu, B. Investigation into partially premixed combustion fueled with n-butanol-diesel blends. Renew. Energy 2016, 86, 723-732. [CrossRef]

2. Kumar, V.; Gupta, D.; Naseer Siddiquee, M.W.; Nagpal, A.; Kumar, V. Performance and emission characteristics of n-butanol and iso-butanol diesel blend comparison. SAE Tech. Paper 2015, 1, 2819.

3. Cai, Y.; Jia, M.; Xu, G.; Li, Y.; Wang, T. Feasibility study of the combustion strategy of n-butanol/diesel dual direct injection (DI $\left.{ }^{2}\right)$ in a compression-ignition engine. Fuel 2021, 289, 119865. [CrossRef]

4. Galloni, E.; Fontana, G.; Scala, F. Experimental and numerical analyses of a spark-ignition engine firing with n-butanol-gasoline blends at high load operation. Energy Procedia 2018, 148, 336-343. [CrossRef]

5. Blin, J.; Brunschwig, C.; Chapuis, A.; Changotade, O.; Sidibe, S.; Noumi, E.; Girard, P. Characteristics of vegetable oils for use as fuel in stationary diesel engines-Towards specifications for a standard in West Africa. Renew. Sustain. Energy Rev. 2013, 22, 580-597. [CrossRef]

6. Han, J.; He, W.; Somers, L.M.T. Experimental investigation of performance and emissions of ethanol and n-butanol fuel blends in a heavy-duty diesel engine. Front. Mech. Eng. 2020, 6, 26. [CrossRef]

7. Tian, W.; Zhang, H.; Wang, L.; Han, Z.; Yu, W. Effect of premixed n-butanol ratio on the initial stage of combustion in a light-duty butanol/diesel dual-fuel engine. Energies 2020, 13, 4295. [CrossRef]

8. Kuszewski, H.; Jakubowski, M.; Jaworski, A.; Lubas, J.; Balawender, K. Effect of temperature on tribological properties of 1-butanol-diesel fuel blends-Preliminary experimental study using the HFRR method. Fuel 2021, 296, 120700. [CrossRef]

9. Sahin, Z.; Durgun, O.; Aksu, O.N. Experimental investigation of n-butanol/diesel fuel blends and n-butanol fumigationEvaluation of engine performance, exhaust emissions, heat release and flammability analysis. Energy Convers. Manag. 2015, 103, 778-789. [CrossRef]

10. Pan, M.; Wang, Y.; Qian, W.; Wu, C.; Huang, H.; Li, H.; Zhou, X. Experimental and numerical study on flow, combustion and emission characteristics of CI engine fueled with n-butanol/diesel blends under post-injection strategy. Fuel 2021, $292,120267$. [CrossRef]

11. Jamrozik, A.; Tutak, W.; Gnatowska, R.; Nowak, Ł. Comparative analysis of the combustion stability of diesel-methanol and diesel-ethanol in a dual fuel engine. Energies 2019, 12, 971. [CrossRef]

12. Di Blasio, G.; Beatrice, C.; Molina, S. Effect of Port Injected Ethanol on Combustion Characteristics in a Dual-Fuel Light Duty Diesel Engine; No. 2013-01-1692; SAE Technical Paper: Troy, MI, USA, 2013.

13. Shamun, S.; Belgiorno, G.; Di Blasio, G.; Beatrice, C.; Tunér, M.; Tunestål, P. Performance and emissions of diesel-biodiesel-ethanol blends in a light duty compression ignition engine. Appl. Therm. Eng. 2018, 145, 444. [CrossRef]

14. Belgiorno, G.; Di Blasio, G.; Shamun, S.; Beatrice, C.; Tunestål, P.; Tunér, M. Performance and emissions of diesel-gasoline-ethanol blends in a light duty compression ignition engine. Fuel 2018, 217, 78. [CrossRef]

15. Kim, K.H.; Choi, B.; Park, S.; Kim, E.; Chiaramonti, D. Emission characteristics of compression ignition (CI) engine using diesel blended with hydrated butanol. Fuel 2019, 257, 116037. [CrossRef]

16. Dev, S.; Gao, T.; Yu, X.; Ives, M.; Zheng, M. Fuel stratification and partially premixed combustion with neat n-butanol in a compression ignition engine. J. Eng. Gas Turb. Power 2018, 140, 122803. [CrossRef]

17. Tang, Q.; Jiang, P.; Peng, C.; Chang, H.; Zhao, Z. Comparison and analysis of the effects of spark timing and lambda on a high-speed spark ignition engine fuelled with n-butanol/gasoline blends. Fuel 2021, 287, 119505. [CrossRef]

18. Hana, D.; Fana, Y.; Sun, Z.; Noura, M.; Lia, X. Combustion and emissions of isomeric butanol/gasoline surrogates blends on an optical GDI engine. Fuel 2020, 272, 117690. [CrossRef]

19. Tutak, W.; Jamrozik, A. Comparative analysis of combustion stability of diesel/ethanol utilization by blend and dual fuel. Processes 2019, 7, 946. [CrossRef]

20. Rakopoulos, D.C.; Rakopoulos, D.C.; Giakoumis, E.G.; Dimaratos, A.M.; Kyritsis, D.C. Effects of butanol-diesel fuel blends on the performance and emissions of a high-speed DI diesel engine. Energy Convers. Manag. 2010, 51, 1989-1997. [CrossRef]

21. Doğan, $\mathrm{O}$. The influence of $\mathrm{n}$-butanol/diesel fuel blends utilization on a small diesel engine performance and emissions. Fuel 2011, 90, 2467-2472. [CrossRef] 
22. Valentino, G.; Corcione, F.E.; Iannuzzi, S.E.; Serra, S. Experimental study on performance and emissions of a high speed diesel engine fuelled with n-butanol diesel blends under premixed low temperature combustion. Fuel 2012, 92, 295-307. [CrossRef]

23. Weall, A.; Collings, N. Investigation into partially premixed combustion in a light-duty multi-cylinder diesel engine fuelled with a mixture of gasoline and diesel. SAE Tech. Pap. 2007, 1, 4058.

24. Tutak, W.; Jamrozik, A.; Gnatowska, R. Combustion of different reactivity fuel mixture in a dual fuel engine. Therm. Sci. 2018, 22, 1191-1203. [CrossRef]

25. Li, J.; Yang, W.; Zhou, D. Review on the management of RCCI engines. Renew. Sustain. Energy Rev. 2017, 69, 65-79. [CrossRef]

26. Olmeda, P.; García, A.; Monsalve-Serrano, J.; Sari, R.L. Experimental investigation on RCCI heat transfer in a light-duty diesel engine with different fuels: Comparison versus conventional diesel combustion. Appl. Therm. Eng. 2018, 144, 424-436. [CrossRef]

27. Pandian, M.M.; Anand, K. Experimental optimization of reactivity controlled compression ignition combustion in a light duty diesel engine. Appl. Therm. Eng. 2018, 138, 48-61. [CrossRef]

28. Krishnamoorthi, M.; Malayalamurthi He, Z.; Kandasamy, S. A review on low temperature combustion engines: Performance, combustion and emission characteristics. Renew. Sustain. Energy Rev. 2019, 116, 109404. [CrossRef]

29. Pan, M.; Tong, C.; Qian, W.; Lu, F.; Yin, J.; Huang, H. The effect of butanol isomers on diesel engine performance, emission and combustion characteristics under different load conditions. Fuel 2020, 277, 118188. [CrossRef]

30. Karagöz, M. Investigation of performance and emission characteristics of an CI engine fuelled with diesel-waste tire oil-butanol blends. Fuel 2020, 282, 118872. [CrossRef]

31. Xiao, H.; Guo, F.; Li, S.; Wang, R.; Yang, X. Combustion performance and emission characteristics of a diesel engine burning biodiesel blended with n-butanol. Fuel 2019, 258, 115887. [CrossRef]

32. Altun, S.; Öner, C.; Yaşar, F.; Adin, H. Effect of n-butanol blending with a blend of diesel and biodiesel on performance and exhaust emissions of a diesel engine. Ind. Eng. Chem. Res. 2011, 50, 9425-9430. [CrossRef]

33. Kattela, S.P.; Vysyaraju, R.K.R.; Surapaneni, S.R.; Ganji, P.R. Effect of n-butanol/diesel blends and piston bowl geometry on combustion and emisson characteristics of CI engine. Environ. Sci. Pollut. Res. 2019, 26, 1661-1674. [CrossRef]

34. Jamrozik, A.; Cupiał, K.; Gruca, M.; Grzelka, J.; Kociszewski, A.; Pyrc, M.; Tutak, W. Analysis of correlation between an electric current fluctuation and selected operating parameters of the gas generator set. Electr. Rev. 2012, 88, $238-243$.

35. Zhou, X.; Qian, W.; Pan, M.; Huang, R.; Xu, L.; Yin, Y. Potential of n-butanol/diesel blends for CI engines under post injection strategy and different EGR rates conditions. Energy Convers. Manag. 2020, 204, 112329. [CrossRef]

36. Jamrozik, A.; Tutak, W.; Pyrc, M.; Gruca, M.; Kočiško, M. Study on co-combustion of diesel fuel with oxygenated alcohols in a compression ignition dual-fuel engine. Fuel 2018, 221, 329-345. [CrossRef]

37. Zhang, Q.; Yang, C.; Li, Y. Effects of ethanol, n-butanol, and n-pentanol addition to diesel fuel on combustion and emission characteristics in a common-rail diesel engine with exhaust-gas recirculation. J. Energy Eng. 2021, 147, 04020086. [CrossRef]

38. Monsalve-Serrano, J.; Belgiorno, G.; Di Blasio, G.; Guzmán-Mendoza, M. 1d simulation and experimental analysis on the effects of the injection parameters in methane-diesel dual-fuel combustion. Energies 2020, 13, 3734. [CrossRef]

39. Heywood, J.B. Internal Combustion Engine Fundamentals, 2nd ed.; McGraw-Hill Education: New York, NY, USA, 2018.

40. Singh, R.; Singh, S.; Kumar, M. Impact of n-butanol as an additive with eucalyptus biodiesel-diesel blends on the performance and emission parameters of the diesel engine. Fuel 2020, 277, 118178. [CrossRef]

41. Tutak, W.; Jamrozik, A. Influence of gasoline addition on biodiesel combustion in a compression-ignition engine with constant settings. Processes 2020, 8, 1499. [CrossRef]

42. Wei, L.; Geng, P. A review on natural gas/diesel dual fuel combustion, emissions and performance. Fuel Process. Technol. 2016, 142, 264-278. [CrossRef]

43. Semakula, M.; Inambao, F. The formation, effects and control of oxides of nitrogen in diesel engines. Int. J. Appl. Eng. Res. 2018, 13, 3200-3209.

44. Semakula, M.; Inambao, F. The effects of exhaust gas recirculation on the performance and emission characteristics of a diesel engine-A critical review. Int. J. Appl. Eng. Res. 2017, 12, 13677-13689. 